\title{
ESTUDO DE REAÇÕES EXPANSIVAS EM ARGAMASSAS DE CIMENTO PORTLAND COM CINZA DE CASCA DE ARROZ (CCA)
}

\section{STUDY OF EXPANSIVE REACTIONS IN MORTAR MADE OF PORTLAND CEMENT WITH RICE HUSK ASH (RHA)}

\section{Silva, E. J. ${ }^{1}$, Tashima, M. M. ${ }^{2}$; Akasaki, J. L. ${ }^{3}$}

${ }^{1}$ Aluno de Graduação , Universidade Estadual Paulista - UNESP, Campus de Ilha Solteira, e-mail: js_everton@yahoo.com.br

${ }^{2}$ Aluno de Pós-Graduação, Universidade Estadual Paulista - UNESP, Campus de Ilha Solteira, e-mail: mmtashima@aluno.feis.unesp.br

${ }^{3}$ Professor Adjunto, Departamento de Engenharia, Universidade Estadual Paulista UNESP - Campus de Ilha Solteira e-mail: akasaki@dec.feis.unesp.br Alameda Bahia, 550 - Centro - 15385-000 - Ilha Solteira - SP - Fone: (18) 37431213.

\section{RESUMO}

A casca de arroz é um resíduo agroindustrial que adequadamente queimada e moída, pode se tornar uma importante pozolana a ser adicionada em argamassas. Um fator que viabiliza o seu emprego, é que dos 10 milhões de toneladas de arroz que o país produz por ano, sobram dois milhões de toneladas de casca - que podem render cerca de 400 mil toneladas de cinza, o suficiente para suprir o mercado de argamassas, concreto e outros. Esta grande quantidade de material produzido passa a se tornar um problema, porque acaba sendo descartada de modo inadequado, gerando poluição no meio ambiente. No sentido de encontrar uma finalidade viável para a utilização de cinza de casca de arroz na construção civil, o presente trabalho estuda a variação do comportamento de argamassas com diferentes teores de CCA. (Cinza de Casca de Arroz). Trabalhou-se com corpos-de-prova prismáticos, com dimensões de $25 \times 25 \times 285 \mathrm{~mm}$, moldados com $0 \%$ (referência), 5\%, 10\% e $25 \%$ de CCA, em substituição em massa ao cimento. A influência da cinza foi constatada através dos seguintes ensaios: eficiência de materiais pozolânicos em evitar a expansão e reação álcali-agregado. O resultado obtido no ensaio de redução da expansão (NBR 12651) mostrou que a CCA reduz consideravelmente a expansão de argamassas devido à reação com o álcalis do cimento $(94,29 \%)$, quando o limite mínimo de redução 
exigido pela norma para uma pozolana é de $75 \%$. Embora no ensaio de reação álcaliagregado (ASTM C-1260) os valores de expansão tenham ficado acima do limite permitido para considerar o material inócuo, tanto o teor de $5 \%$ quanto o de $10 \%$ de CCA obtiveram resultados melhores (expandiram menos) que o traço de referência.

Palavras-chave: Pozolana. Cinza de casca de arroz. Argamassa. Resíduo agroindustrial.

\section{ABSTRACT}

Rice husk is an agroindustrial residue which, when adequately burned and ground, may become an important pozzolan to be added in mortars. One factor contributing to the feasibility of its use is that of the 10 million tons of rice produced annually in this country, two million tons of husk remain, which can produce about 400 thousand tons of ash - enough to supply the market for mortars, concrete and others. This large amount of material has become an environmental problem because it is being discarded inappropriately. Seeking a viable use of rice husk ash in the civil construction, the present research studies the variation in mortar behavior with different levels of RHA (Rice Husk Ash). Prismatic specimens were used, measuring $25 \times 25 \times 285 \mathrm{~mm}$, moulded with $0 \%$ (reference), $5 \%, 10 \%$ and $25 \%$ RHA. The influence of the RHA's was verified through the following tests: efficiency of pozzolanic materials in avoiding expansion and alkali-aggregate reaction. The result obtained in the expansion reduction test (NBR 12651) showed that RHA reduces considerably the expansion of mortars due to reaction with the alkalis in the cement $(94.29 \%)$, with the minimum reduction required by the norm for a pozolan being $75 \%$. Although the expansion values in the alkali-aggregate reaction test (ASTM C1260) remained above the limit allowed to consider the material innocuous, RHA levels of $5 \%$ as well as $10 \%$ obtained better results (expanded less) then the reference line.

Key-words: Pozzolan. Rice husk ash. Mortar. Agroindustrial residue.

\section{INTRODUÇÃO}

O reaproveitamento de resíduos aparece nos dias atuais como questão fundamental na melhoria do meio ambiente, tanto em função da redução de desperdícios de recursos naturais, quanto na minimização dos impactos ambientais oriundos da disposição final dos resíduos.

A casca de arroz é um subproduto resultante do beneficiamento de arroz. A própria indústria de beneficiamento utiliza a casca, que tem alto poder calorífico, nos processos de secagem dos grãos. A geração de energia através da queima da casca de arroz é uma alternativa praticável do ponto de vista tecnológico, viável do ponto de 
vista econômico, e aceitável do ponto de vista ecológico. No caso da geração de energia pela combustão direta, o resíduo final é a cinza impura. Se ela for utilizada, direta ou indiretamente, para algum fim comercial, se fechará o ciclo da industrialização do arroz, sendo possível o total aproveitamento da matéria-prima proveniente da lavoura, já que o farelo, gérmen e outras partes já têm seu destino no mercado.

Um fator que viabiliza seu emprego é que a produção mundial de arroz está estimada em 500 milhões de toneladas, sendo o Brasil um dos dez maiores produtores com uma produção de aproximadamente 13.251.200 de toneladas no ano de 2004 (IBGE, 2005).

Contudo, esta grande quantidade de material produzido terá valor econômico se tiver alta qualidade, que é mensurada pela alta superfície específica, tamanho e pureza de partícula. Conseqüentemente, seria um grande desperdício de matériaprima nobre jogá-la fora, já que pode ser usada em vários ramos industriais, tais como eletrônica, construção civil, cerâmica, indústria química, fabricação de células fotovoltaicas, entre outros.

Um trabalho realizado por Foletto et al (2005) confere algumas alternativas tecnológicas para a utilização de cinza de casca de arroz:

$>$ Produção de carbeto de silício (SiC)

$>$ Produção de sílica pura

$>$ Utilização da cinza como carga em polímeros

Uso de cinzas como adsorventes

Uso de cinza como suporte de catalisadores metálicos

Síntese de zeólitas

Produção de diferentes tipos de silicatos

No caso da construção civil, como o material é adicionado conjuntamente ao cimento Portland, muitas propriedades únicas apresentadas pela cinza de casca de arroz têm sido reportadas por diversos pesquisadores. Com o concreto fresco, adições de misturas pozolânicas, tais como a CCA, têm a capacidade de reduzir a segregação e a exudação, e isto acarreta em grande melhoria da trabalhabilidade. Exceto a cinza de casca de arroz, nenhum outro material pozolânico, incluindo-se a sílica ativa, tem a habilidade de contribuir para o aumento na resistência mecânica do concreto em baixas idades, como 1 e 3 dias. Isto abre as portas para o uso de misturas de cinza volante e outras pozolanas normais com a CCA, com a última agindo como acelerador de resistência (MEHTA, 1992).

A ASTM C 618 (ASTM,1978) e a NBR 12653 (ABNT, 1992b) definem pozolana como um material que, por si só, possui pouca ou nenhuma atividade cimentícea, mas que, quando finamente dividido e na presença de água, reage com o hidróxido de cálcio à temperatura ambiente para formar compostos com propriedades cimentantes. 
Dependendo do processo de queima da casca, as características da cinza obtida podem variar bastante. O objetivo é o de obter sílica amorfa para agir como material pozolânico. Entretanto, algumas vezes são encontradas formas cristalinas da sílica se o processo não for bem controlado. Os fatores determinantes da qualidade da cinza são: a temperatura da combustão, o tempo de combustão e o ambiente da combustão (COOK 1984). Segundo Della et al. (2001), quando a temperatura de queima da CCA é baixa ou quando o tempo de exposição da mesma a altas temperaturas é pequeno, a ślica contida na cinza é predominantemente amorfa. Ou seja, quanto menos tempo a cinza ficar exposta a uma elevada temperatura, menos cristalização ocorre. Sugita et al. (1997) diz que se a casca sofrer um processo controlado de elevação da temperatura antes de se iniciar a combustão, ela pode permanecer por um período longo durante a combustão com temperaturas acima de $1000^{\circ} \mathrm{C}$ sem ocorrer nenhuma cristalização.

Um estudo realizado por Rego (2004a) revelou que embora a quantidade de sílica entre diferentes CCAs, amorfa e cristalina, fosse pequena, a diferença no teor de amorficidade é muito significativa. Enquanto a CCA amorfa está $100 \%$ nessa estrutura, a CCA cristalina tem apenas $6,35 \%$ de material com estrutura amorfa sendo o restante $(93,65 \%)$ composto por sílica cristalina, ele também observou através do ensaio de granulometria a laser, que os diâmetros médios das CCAs apresentaram resultados muito próximos.Um fator importante no uso da CCA é o grau de moagem. Em termos de características físicas, as mais importantes são as relacionadas com a finura, em todas as suas manifestações e expressões, já que frações granulométricas diferentes se comportam de maneira diferente.

Rego (2004b) desenvolveu um trabalho comparando CCAs cujas estruturas eram amorfas e cristalinas. Ele chegou à conclusão que ambas as CCAs apresentaram aumento do IAP (índice de atividade pozolânica) com a diminuição do diâmetro médio das partículas. Quando finamente divididas tanto a CCA amorfa quanto a cristalina mostraram-se altamente pozolânicas em relação a esse ensaio.

No que diz respeito à Reação álcali-agregado (RAA), ela pode ser definida como um termo geral utilizado para descrever a reação química que ocorre internamente em uma estrutura de concreto, envolvendo os hidróxidos alcalinos provenientes principalmente do cimento e alguns minerais reativos presentes no agregado utilizado. Como resultado da reação, são formados produtos que, na presença de umidade, são capazes de expandir, gerando fissurações, deslocamentos e podendo levar a um comprometimento das estruturas de concreto. Segundo Mehta e Monteiro (1994), as expansões e fissurações provocadas pela RAA podem comprometer a resistência e elasticidade de um concreto afetando, por conseguinte, a sua durabilidade. Ressalta-se que a principal causa da instalação da RAA é a presença, no agregado, de minerais reativos que reagem com os álcalis do cimento. Entretanto, influências externas como a umidade e temperatura são condicionantes importantes do processo deletério (HOBBS, 1988). A reação álcali-agregado é 
dividida em três categorias, em função da composição mineralógica reativa do agregado: reação álcali-sílica, álcali-silicato e álcali-carbonato.

A reação álcali-sílica é a mais conhecida e a que ocorre mais rapidamente (KIHARA, 1986). Segundo Hobbs (1988), a opala ou sílica amorfa pode ser considerada como a forma mais desordenada e reativa de sílica. Kihara (1986), Hobbs (1988) relatam que entre os minerais do grupo da sílica considerados reativos, encontram-se também a calcedônia, que é uma variedade de quartzo fibroso ou criptocristalino, a cristobalita e a tridimita, que são formas cristalizadas metaestáveis de sílica, os vidros naturais ou vulcânicos, que possuem uma estrutura amorfa sendo encontrados em depósitos piroclásticos ou rochas vulcânicas, e os vidros artificiais, como por exemplo, o pirex. O produto desta reação é o gel expansivo.

A reação álcali-silicato é apresentada por Hobbs (1988) como sendo a reação que ocorre entre os álcalis presentes na solução dos poros do concreto e alguns minerais do grupo dos filossilicatos. Segundo Kihara (1986), existem vários agregados susceptíveis de causarem reação, porém o pesquisador relata que a reação álcali-silicato está basicamente ligada à presença do quartzo "tensionado", ocasionado por processos tectônicos ou metamórficos, ou de minerais expansivos do grupo dos filossilicatos, tais como as vermiculitas, ilitas e montmorilonitas. Hobbs (1988) comenta que apesar da reação álcalisilicato ocorrer mais lentamente do que a reação álcali-sílica, o mesmo produto da reação álcali-sílica (gel) pode ser encontrado no concreto afetado pela reação álcali-silicato.

A reação álcali-carbonato é completamente distinta das reações álcali-sílica e álcali-silicato. Ela ocorre entre os álcalis disponíveis do cimento e alguns agregados carbonáticos como os calcários dolomíticos argilosos. Nesta reação não há a formação do gel (KIHARA, 1986). Os resultados são fissurações e o enfraquecimento da zona de transição entre a pasta de cimento e o agregado (BERRA et al., 1991).

Um estudo realizado por Hasparyk (1999) mostra que os resultados de expansão obtidos no ensaio de reatividade mostraram que a cinza de casca de arroz se comporta de maneira eficiente no combate da RAA, apresentando comportamento similar ao da sílica ativa. Woglon et al. (2002) também estudou a adição de cinza de casca de arroz no combate a RAA. O autor relata que a eficiência da incorporação de CCA depende da reatividade do agregado. Segundo ele, o teor de $25 \%$ de substituição de CCA por cimento apresentou um comportamento contrário ao teor de $50 \%$. O primeiro considerado péssimo e o segundo ótimo.

No presente trabalho, foi feito uso da CCA residual, ou seja, produzida sem controle de temperatura, mas observando a variação da temperatura ao longo do tempo de queima. Um processo de queima com controle de temperatura pode inviabilizar financeiramente a produção de CCA.

Visando avaliar o quanto à adição da CCA pode diminuir a reação álcaliagregado foram executados dois ensaios de reatividade: ASTM C-1260 (1994) e NBR 12651 (1992). Assim, além de se verificar o efeito da incorporação de CCA, 
será possível comparar os dois métodos de ensaio, visto que não há registros na literatura comparando os métodos apresentados.

\section{MATERIAIS}

\subsection{Obtenção e Moagem}

$\mathrm{Na}$ presente pesquisa utilizou-se uma cinza obtida pela queima não controlada da casca de arroz, mas com verificação da temperatura. A casca de arroz foi obtida numa máquina de beneficiamento de arroz localizada na cidade de Andradina, SP. O tempo de queima da cinza foi de aproximadamente 36 horas com a temperatura variando entre a ambiente e $850^{\circ} \mathrm{C}$. Depois de queimada, a cinza foi levada para um processo de moagem, em um moinho de bolas, no Laboratório Central de Engenharia Civil da CESP. O tempo de moagem foi de 30 minutos e suas características físicoquímicas foram determinadas. O Quadro 1 mostra os resultados desta caracterização e na Figura 1 há uma amostra de CCA após ter passado pelos processos de queima e moagem.

\section{Quadro 1. Caracterização físico-química da CCA}

\begin{tabular}{|c|c|c|c|c|}
\hline \multicolumn{2}{|r|}{ Ensaios } & & \multicolumn{2}{|c|}{ Especificações NBR-12653 } \\
\hline \multicolumn{2}{|c|}{ Densidade absoluta $\quad\left(\mathrm{g} / \mathrm{cm}^{3}\right)$} & 2,16 & mínimo & Máximo \\
\hline \multirow{3}{*}{$\begin{array}{c}\text { Índices } \\
\text { atividade } \\
\text { pozolânica }\end{array}$} & \begin{tabular}{|l|} 
Água requerida (\%) \\
\end{tabular} & 114,6 & - & 110,0 \\
\hline & Com cimento $(\%)$ & 74,8 & 75,0 & - \\
\hline & Com cal (MPa) & 4,9 & 6,0 & - \\
\hline+2 & Umidade (\%) & 1,90 & - & 3,00 \\
\hline \multirow{13}{*}{$\begin{array}{c}\text { Análise } \\
\text { Química } \\
(\%)\end{array}$} & \begin{tabular}{|l|} 
Perda ao fogo \\
\end{tabular} & 2,36 & - & 6,0 \\
\hline & Insolúveis & 91,93 & - & - \\
\hline & $\mathrm{SiO}_{2}$ & 92,99 & - & - \\
\hline & $\mathrm{Fe}_{2} \mathrm{O}_{3}$ & 0,43 & - & - \\
\hline & $\mathrm{Al}_{2} \mathrm{O}_{3}$ & 0,18 & - & - \\
\hline & $\mathrm{CaO}$ & 1,03 & - & - \\
\hline & $\mathrm{MgO}$ & 0,35 & - & - \\
\hline & $\mathrm{SO}_{3}$ & 0,10 & - & 5,0 \\
\hline & $\mathrm{Al}_{2} \mathrm{O}_{3}+\mathrm{Fe}_{2} \mathrm{O}_{3}$ & 0,61 & - & - \\
\hline & $\mathrm{SiO}_{2}+\mathrm{Al}_{2} \mathrm{O}_{3}+\mathrm{Fe}_{2} \mathrm{O}_{3}$ & 93,50 & 70,00 & - \\
\hline & $\mathrm{Na}_{2} \mathrm{O}$ & 0,02 & - & - \\
\hline & $\mathrm{K}_{2} \mathrm{O}$ & 0,72 & - & - \\
\hline & Equiv alcalino $\mathrm{Na}_{2} \mathrm{O}$ & 0,49 & - & - \\
\hline
\end{tabular}




\begin{tabular}{|l|r|}
\hline Recebido em: $31 / 05 / 2006$ & HOLOS Environment, v.7 n.1, 2007 - P. 78 \\
\hline Liberado para Publicação em: $12 / 06 / 2007$ & ISSN:1519-8421 (CD-ROM) / ISSN:1519-8634 (ON-LINE) \\
\hline
\end{tabular}

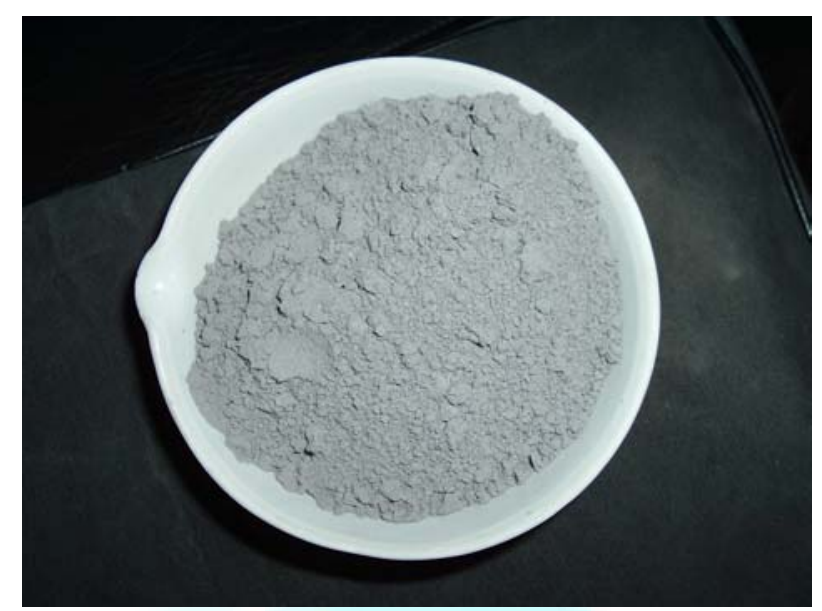

Figura 1. Amostra de CCA após a moagem

\subsection{Cimento}

No ensaio que segue a norma American Society for Testing and Materials C-1260 (ASTM, 1994) foi utilizado o CP II-F-32 Cauê. Já para o ensaio que segue a norma NBR 12651 (ABNT, 1992a), foi utilizado o CP II-F-32 Ribeirão. Estes cimentos foram adotados por melhor se enquadrarem às exigências da norma de cada ensaio; como por exemplo, a presença obrigatória de álcalis-solúveis no cimento. Os cimentos utilizados nos ensaios estão com suas características físicas, químicas e mecânicas atendendo as normas da ABNT.

\subsection{Agregados}

- Vidro Pirex

No ensaio de eficiência de materiais pozolânicos em evitar a expansão, assim como indica a norma, foi utilizado o vidro pirex como agregado, com uma faixa granulométrica disposta no Quadro 2 á seguir:

\section{Quadro 2. Frações do agregado}

\begin{tabular}{|c|c|c|c|}
\hline Peneiras & Porcentagem & Peso(g) & $\begin{array}{c}\text { Peso } \\
\text { Acumulado(g) }\end{array}$ \\
\hline 8 & 10 & 90 & 90 \\
\hline 14 & 25 & 225 & 315 \\
\hline 28 & 25 & 225 & 540 \\
\hline 48 & 25 & 225 & 765 \\
\hline 100 & 15 & 135 & 900 \\
\hline
\end{tabular}

Uma amostra do vidro pirex utilizado no ensaio está representado na Figura 2, após ter passado por um processo de lavagem e secagem. 


\begin{tabular}{|l|r|}
\hline Recebido em: $31 / 05 / 2006$ & HOLOS Environment, v.7 n.1, 2007 - P. 79 \\
\hline Liberado para Publicação em: $12 / 06 / 2007$ & ISSN:1519-8421 (CD-ROM) / ISSN:1519-8634 (ON-LINE) \\
\hline
\end{tabular}

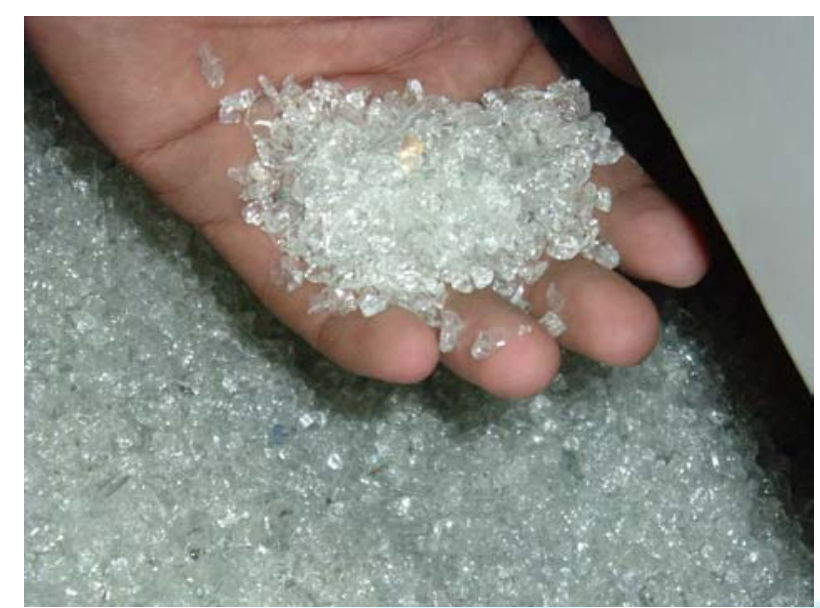

Figura 2. Amostra de Vidro Pirex

- Basalto

Para o ensaio de reação álcali-agregado, o agregado reativo utilizado foi o basalto. As amostras do agregado basalto (Figura 3) foram inicialmente britadas para redução de diâmetro utilizando-se para tal um moinho de lâminas. Posteriormente foram separadas nas frações de acordo com a norma ASTM - C1260, secos em estufa. O Quadro 3 mostra as frações do agregado usado:

Quadro 3. Frações do agregado

\begin{tabular}{|l|l|l|l|}
\hline Peneiras & Porcentagem & Peso(g) & $\begin{array}{c}\text { Peso } \\
\text { Acumulado(g) }\end{array}$ \\
\hline $\mathbf{8}$ & $\mathbf{1 0}$ & $\mathbf{9 0}$ & $\mathbf{9 0}$ \\
\hline $\mathbf{1 6}$ & $\mathbf{2 5}$ & $\mathbf{2 2 5}$ & $\mathbf{3 1 5}$ \\
\hline $\mathbf{3 0}$ & $\mathbf{2 5}$ & $\mathbf{2 2 5}$ & $\mathbf{5 4 0}$ \\
\hline $\mathbf{5 0}$ & $\mathbf{2 5}$ & $\mathbf{2 2 5}$ & $\mathbf{7 6 5}$ \\
\hline 100 & 15 & 135 & $\mathbf{9 0 0}$ \\
\hline
\end{tabular}

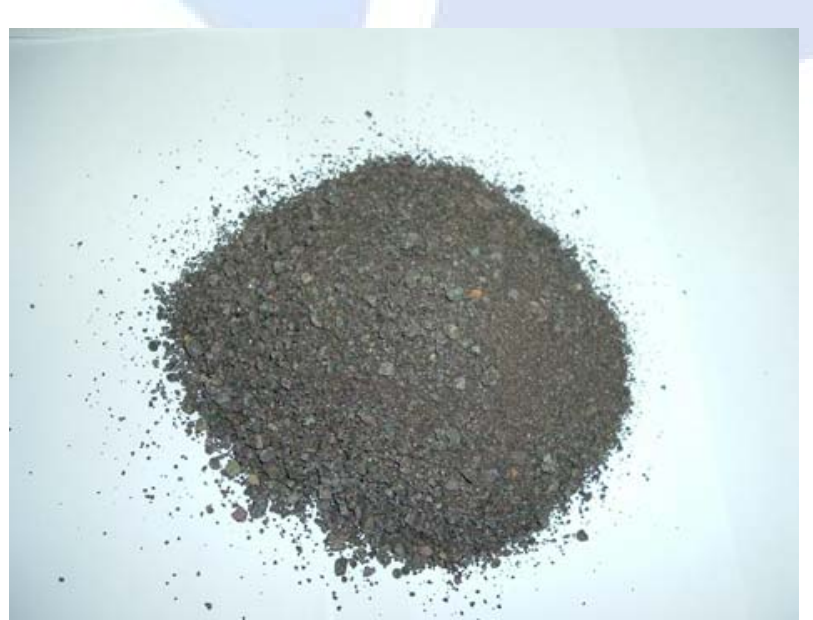

Figura 3. Amostra de basalto 


\begin{tabular}{|l|r|}
\hline Recebido em: $31 / 05 / 2006$ & HOLOS Environment, v.7 n.1, 2007 - P. 80 \\
\hline Liberado para Publicação em: $12 / 06 / 2007$ & ISSN:1519-8421 (CD-ROM) / ISSN:1519-8634 (ON-LINE) \\
\hline
\end{tabular}

\section{METODOLOGIA}

\subsection{Ensaio ASTM C- 1260}

O método de reatividade acelerado utilizado tem como objetivo investigar a reação através do acompanhamento da variação de comprimento de barras de argamassa. A medição desta variação é feita com um comparador de comprimentos com precisão de $0,001 \mathrm{~mm}$ (Figura 4). Foram confeccionadas três barras de argamassa nas dimensões de $25 \mathrm{~mm}$ x $25 \mathrm{~mm}$ x $285 \mathrm{~mm}$ com relação cimento: agregado 1: 2,25 (em massa) e uma relação água/cimento igual a 0,47 . As porcentagens de substituição ao cimento por CCA adotadas foram de 5 e $10 \%$. Estes teores foram usados para que fosse possível verificar se a CCA influencia na diminuição da reação álcali-agregado com pequenas porcentagens de substituição ao cimento.

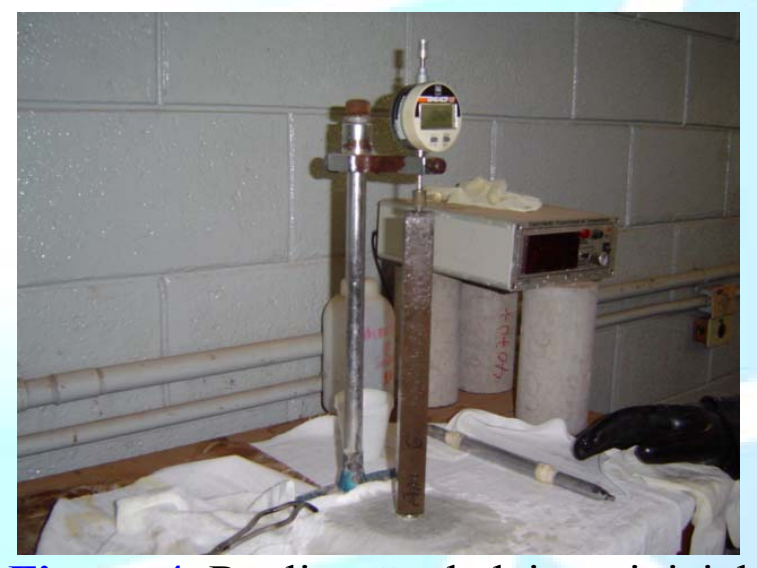

Figura 4. Realização da leitura inicial

De acordo com a norma, as barras foram imersas em solução de hidróxido de sódio $(\mathrm{NaOH})$ a $1 \mathrm{~N}$ à temperatura de $80^{\circ} \mathrm{C}$ por 16 dias (Figura 5). Entretanto, o ensaio foi prolongado até a idade de 28 dias para uma melhor avaliação do resultado apenas por critério de verificação. Foram realizadas leituras diárias do comprimento das barras. Conforme norma ASTM C-1260 (ASTM 1994), os resultados são interpretados da seguinte forma:

(a) expansões inferiores a $0,10 \%$ aos 16 dias indicam um comportamento inócuo na maioria dos casos;

(b) expansões superiores a $0,20 \%$ aos 16 dias são um indicativo de expansão potencialmente deletéria;

(c) expansões com valores entre $0,10 \%$ e $0,20 \%$ aos 16 dias indicam a possibilidade da presença de agregados com comportamento tanto inócuo quanto deletério. Neste caso, sugere-se levar o ensaio até 28 dias bem como a realização de investigações petrográficas do agregado e concreto através das normas ASTM C-295 e ASTM C856 (ASTM, 2002). 


\begin{tabular}{|l|r|}
\hline Recebido em: $31 / 05 / 2006$ & HOLOS Environment, v.7 n.1, 2007 - P. 81 \\
\hline Liberado para Publicação em: $12 / 06 / 2007$ & ISSN:1519-8421 (CD-ROM) / ISSN:1519-8634 (ON-LINE) \\
\hline
\end{tabular}

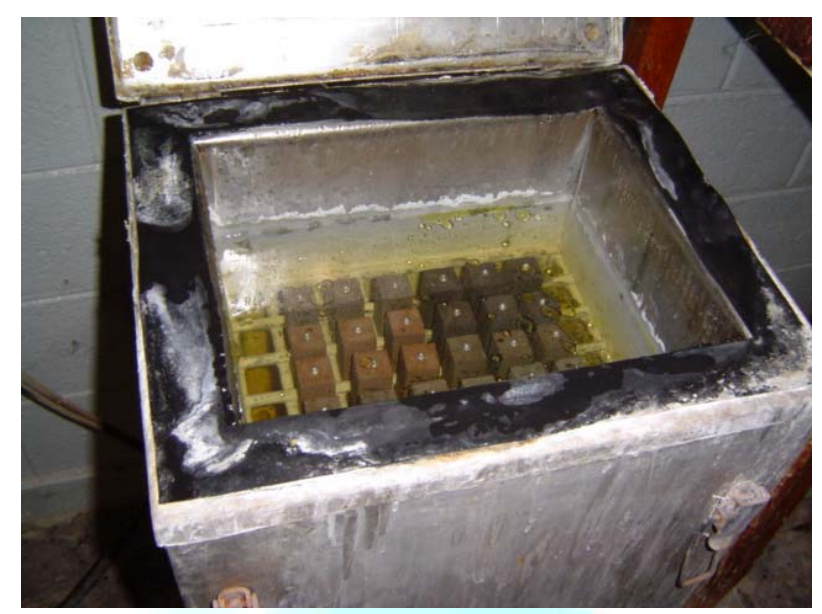

Figura 5. Câmara com $\mathrm{NaOH}$

\subsection{Ensaio NBR 12651}

Este ensaio busca determinar a aptidão de materiais pozalânicos em evitar a expansão causada pela reação entre determinados constituintes dos agregados e os álcalis existentes nas misturas de Cimento Portland, segundo a NBR 12651 (ABNT, 1992a). Esta norma fixa uma porcentagem de substituição ao cimento $(25 \%)$ do material que se pretende estudar para que seja possível ter um índice mínimo de aprovação da norma. No caso, se com este teor de substituição fixo e a trabalhabilidade estiver dentro do intervalo previsto na norma, a argamassa atingir o limite mínimo de redução da expansão exigido, a norma classifica esse material como pozolânico e capaz de reduzir expansões deletérias.

Assim como no primeiro ensaio, foram moldados 3 corpos-de-prova prismáticos com as mesmas dimensões. Logo após a desmoldagem dos corpos-deprova, é realizada a leitura inicial com o mesmo comparador de comprimentos utilizado no ensaio anterior, em seguida, os corpos-de-prova são colocados em recipientes próprios para o ensaio (Figura 6) com uma determinada quantidade de água por 14 dias. Após este período é realizada a leitura final com o comparador de comprimentos.

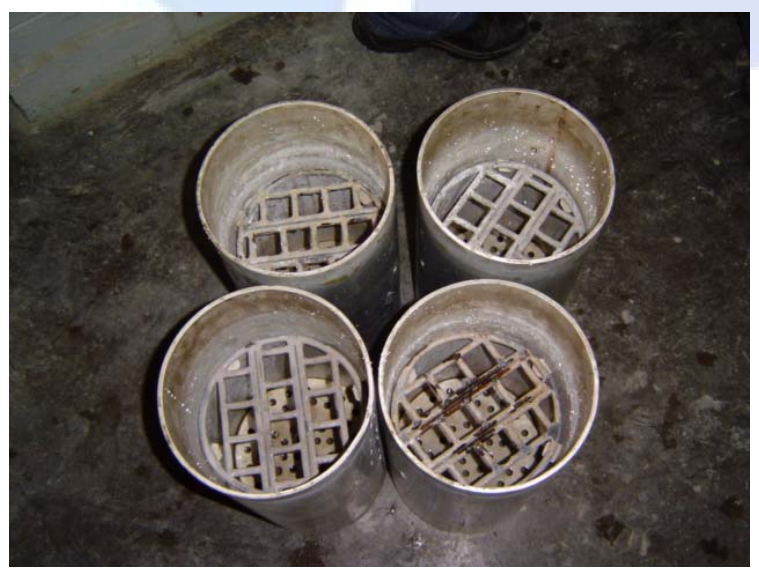

Figura 6. Recipientes para o ensaio 
A redução da expansão da argamassa devida à utilização de material pozolânico deve ser calculada de acordo com a seguinte expressão:

$$
\operatorname{Re}=(E c-E t) \times 100 / E c
$$

onde:

Re é a redução da expansão da argamassa (\%).

Ec é a expansão média das barras de argamassa moldadas com a mistura sem CCA (adimensional).

Et é a expansão média das barras de argamassa moldadas com a mistura com CCA (adimensional).

\section{RESULTADOS E DISCUSSÃO}

\subsection{Ensaio ASTM C- 1260}

A Figura 7 apresenta a variação do comprimento das barras de argamassa do ensaio norma ASTM C-1260 (ASTM, 1994) de acordo com as expansões constatadas com o decorrer dos dias de realização do ensaio.

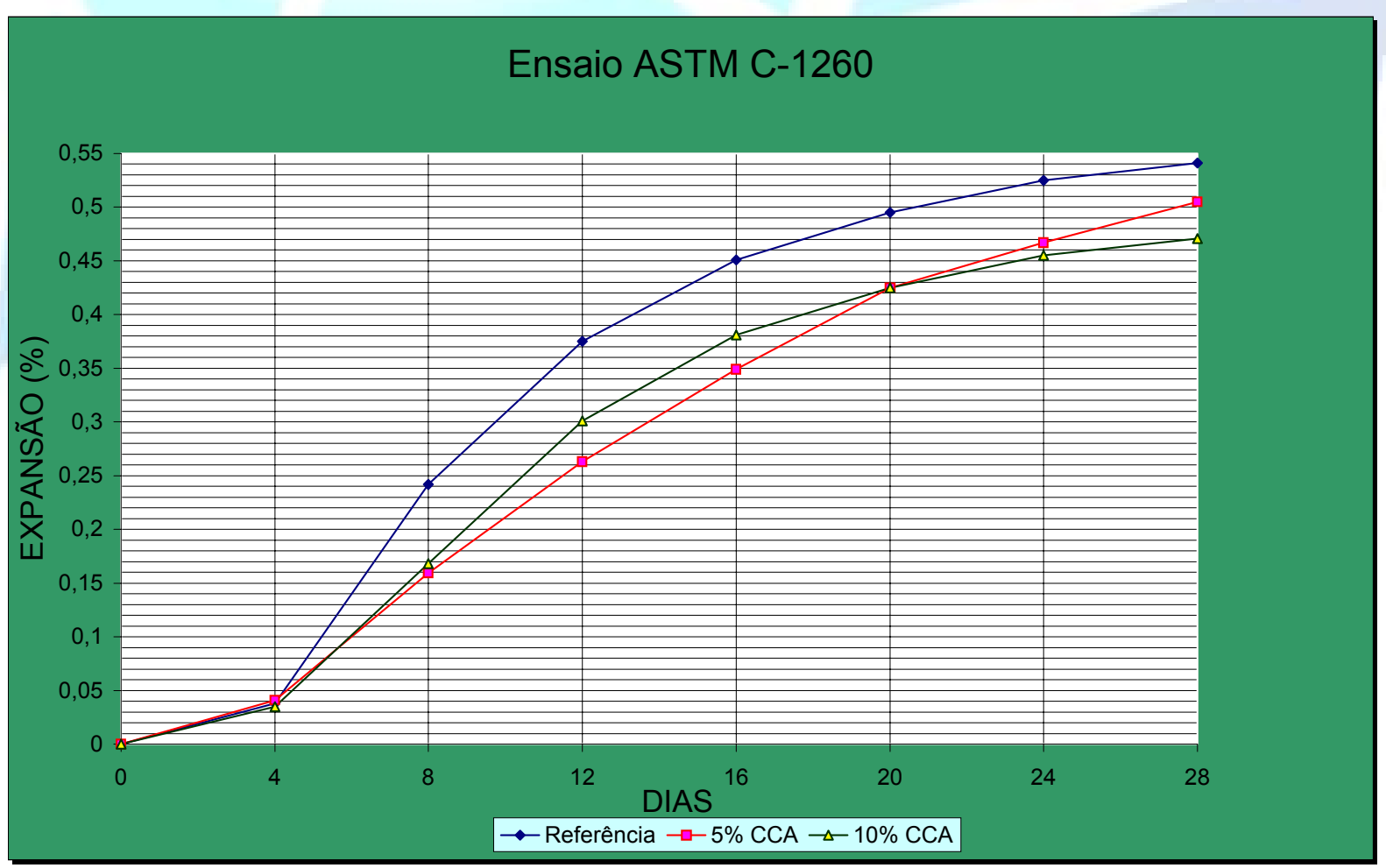

Figura 7. Gráfico do ensaio RAA

Fazendo-se uma análise do gráfico, nota-se que o nível de expansão dos teores de cinza de casca de arroz, a partir do quarto dia, se manteve abaixo do traço de 
referência até o fim de ensaio. No entanto, a norma do ensaio diz que se ao décimo sexto dia, o nível de expansão estiver entre 0,0 e 0,1 (\%), o material pode ser considerado inócuo, ou seja, sem reação. Se o nível estiver entre 0,1 e 0,2 (\%), o material adicionado é considerado potencialmente reativo. A partir destes valores, considera-se o material deletério ou reativo. Dessa forma, embora as porcentagens analisadas tenham reduzido à expansão em relação ao traço de referência; com estes teores de CCA e este tipo de agregado reativo (basalto), o resultado do ensaio foi deletério para os dois teores, uma vez que as expansões verificadas ao décimo sexto dia ficaram muito acima do limite estipulado pela norma, ou seja, a adição de CCA não foi suficiente para inibir a RAA neste caso. Como as expansões não estão no intervalo entre 0,1 e $0,2 \%$, de acordo com a norma, as realizações de investigações petrográficas do agregado podem ser descartadas. Além disso, percebe-se uma sensível diferença no comportamento dos teores de 5 e $10 \%$, o que indica a quantidade de substituição é pequena para se fazer uma análise mais concreta.

\subsection{Ensaio NBR 12651}

Os dados apresentados no Quadro 4 indicam o quanto a adição de CCA reduziu a expansão devido à reação entre os álcalis do cimento e o agregado em relação à expansão do traço referência.

Quadro 4. Redução da expansão

\begin{tabular}{|c|ll|l|l|l|l|}
\hline $\mathbf{N}^{\mathbf{0}} \mathbf{C P}$ & & & $\begin{array}{l}\text { Leitura } \\
\text { Inicial }\end{array}$ & $\begin{array}{l}\text { Leitura } \\
\text { Final }\end{array}$ & EXPANSÃ & $\begin{array}{l}\text { RED.EXP } \\
(\%)\end{array}$ \\
\hline $\mathbf{1}$ & Variedade & Et & 294,123 & 294,137 & 0,005 & \\
\hline $\mathbf{2}$ & & Et & 293,827 & 293,859 & 0,011 & $\mathbf{9 4 , 2 9}$ \\
\hline $\mathbf{3}$ & Et & 294,078 & 294,099 & 0,007 & \\
\hline $\mathbf{1}$ & Ec & 295,076 & 295,499 & 0,143 & \\
\hline $\mathbf{2}$ & Ec & 294,281 & 294,637 & 0,121 & $*$ \\
\hline $\mathbf{3}$ & Ec & 294,071 & 294,468 & 0,135 & \\
\hline
\end{tabular}

De acordo com a norma do ensaio NBR 12651 (ABNT, 1992a), a porcentagem utilizada no ensaio foi de $25 \%$ em relação à massa do cimento. $\mathrm{O}$ *indica que não há um valor de redução da expansão para o traço de referência $(\mathrm{Ec})$, uma vez que seu valor é dado em função do traço de referência.

A partir das leituras iniciais e finais; se calculou as expansões médias. Assim, com auxílio da expressão citada em ENSAIO NBR 12651 (ABNT, 1992a), foi encontrado o significativo valor de $94,29 \%$ de redução da expansão em relação à referência. Isto já é perceptível ao verificar que as expansões médias do traço Et são menores que as do traço Ec. 


\begin{tabular}{|l|r|}
\hline Recebido em: $31 / 05 / 2006$ & HOLOS Environment, v.7 n.1, 2007 - P. 84 \\
\hline Liberado para Publicação em: $12 / 06 / 2007$ & ISSN:1519-8421 (CD-ROM) / ISSN:1519-8634 (ON-LINE) \\
\hline
\end{tabular}

\section{CONCLUSÃO}

De acordo com os resultados desta pesquisa, verificou-se que a adição da cinza de casca de arroz residual nestes ensaios físicos é aceitável. Porém, deve-se levar em consideração as características físico-químicas da Cinza de Casca de Arroz - CCA residual determinadas principalmente pela temperatura de queima e pelo diâmetro médio das partículas. O resultado obtido no ensaio de redução da expansão NBR 12651(ABNT, 1992a) mostrou que a CCA reduz consideravelmente a expansão de argamassas devido à reação com o álcalis do cimento (94,29\%), quando o limite mínimo de redução exigido pela norma para uma pozolana é de $75 \%$. Embora no ensaio de reação álcali-agregado ASTM C-1260 (ASTM, 1994) os valores de expansão tenham ficado acima do limite permitido para considerar o material inócuo, tanto o teor de $5 \%$ quanto o de $10 \%$ de CCA obtiveram resultados melhores (expandiram menos) que o traço de referência.

\section{AGRADECIMENTOS}

- CNPq - Conselho Nacional de Desenvolvimento Científico e Tecnológico.

- Laboratório Central de Engenharia Civil da CESP de Ilha Solteira

\section{REFERÊNCIAS}

ASTM - AMERICAN SOCIETY FOR TESTING AND MATERIALS. Standard Guide for petrographic examination of aggregates for concrete. West Conshohocken, 2003. (ASTM C.295).

ASTM - AMERICAN SOCIETY FOR TESTING AND MATERIALS. Standard specification for fly ash and raw or calcined natural pozzolan for use as a mineral admixture in Portland cement concrete. Philadelphia, 1978. (ASTM C $618)$.

ASTM - AMERICAN SOCIETY FOR TESTING AND MATERIALS. Standard practice for petrographic examination of hardened concrete. West Conshohocken, 2002. (ASTM 856).

ASTM - AMERICAN SOCIETY FOR TESTING AND MATERIALS. Standard test method for potencial alkali reactivity of agregates (Montan-Ban Method). Philadelphia, 1994. (ASTM C 1260).

ABNT. ASSOCIAÇÃO BRASILEIRA DE NORMAS TÉCNICAS. ABNT. NBR 12651: Determinação da eficiência de materiais pozolânicos em evitar a expansão do concreto devido à reação álcali-agregado. Rio de Janeiro, 1992. 


\begin{tabular}{|l|r|}
\hline Recebido em: $31 / 05 / 2006$ & HOLOS Environment, v.7 n.1, 2007 - P. 85 \\
\hline Liberado para Publicação em: 12/06/2007 & ISSN:1519-8421 (CD-ROM) / ISSN:1519-8634 (ON-LINE) \\
\hline
\end{tabular}

ABNT. ASSOCIAÇÃO BRASILEIRA DE NORMAS TÉCNICAS. ABNT. NBR 12653: Materiais pozolânicos - Rio de Janeiro, 1992.

BERRA, M.; BERTACCHI, P. Alkali-aggregate reaction in concrete dams review and recomendations. International Water Power and Dam Construction. IWPCDM, Sutton, v. 43, n. 4, p. 12-16, Apr.,1991. Disponível em:

$\mathrm{http}: / / \mathrm{md} 1 . \mathrm{csa} . \mathrm{com} /$ partners/viewrecord.php?request $=$ gs\&collection=TRD\&recid=20 0162010451CE\&q=\&uid=791396174\&setcookie=yes. Acesso em: 20 nov 2006.

COOK, D. J. Rice Husk Ash. Bishopbriggs, Glasgow: Surrey University Press, 1984.p. 171-196. (Concrete Tecmology and Desing, vol.3).

DELLA, V. P.; KÜHN, I.; HORTZA, D.Caracterização de cinza de casca de arroz para o uso como matéria-prima na fabricação de refratários de sílica. Revista Química Nova. vol. 24, no. 06, 778-782, 2001.

FOLETTO, E. L.; HOFFMAN R., et al. Aplicabilidade das Cinzas da Casca de Arroz. Revista Química Nova. Vol. 28, No. 6, 1055-1060, 2005.

HASPARYK; N. P. Investigação dos mecanismos da reação álcali-agregado efeito da cinza de casca de arroz e da sílica ativa. 1999. 257p. Dissertação (Mestrado em Engenharia Civil) Escola de Engenharia Civil, Universidade Federal de Goiás, Goiânia,1999,

HOBBS, D. W. Alkali-silica reaction in concrete. London: Thomas Telford, 1988. $183 p$.

IBGE. INSTITUTO BRASILEIRO DE GEOGRAFIA E ESTATÍSTICA; Indicadores conjunturais: produção agrícola. Disponível em:

\{HYPERLINK http://www.ibge.gov.br\}. Acesso em 20 nov. 2006.

KIHARA, Y. Reação álcali-agregado: aspectos mineralógicos. In: SIMPÓSIO NACIONAL DE AGREGADOS, 1., 1986, São Paulo. Anais... São Paulo: Escola Politécnica da USP, 1986. p. 127-138.

MEHTA, P.K. Rice husk ash: a unique suplementary cementing material. Ottawa: Canadá Centre for Mineral and Energy Technology. 1992. p 407-431. (Advances in Concrete Technology).

MEHTA, P. K.; MONTEIRO, P. J. M. Concreto: estrutura, propriedades e materiais. São Paulo: Pini, 1994. 


\begin{tabular}{|l|r|}
\hline Recebido em: $31 / 05 / 2006$ & HOLOS Environment, v.7 n.1, 2007 - P. 86 \\
\hline Liberado para Publicação em: 12/06/2007 & ISSN:1519-8421 (CD-ROM) / ISSN:1519-8634 (ON-LINE) \\
\hline
\end{tabular}

REGO, J. H. S. Estudo de Aglomerantes compostos por cimento portland comum (CPI) e as cinzas de CA amorfa e cristalina. In CONGRESSO BRASILEIRO DO CONCRETO, 46., 2004a, Florianópolis.Anais...Florianópolis IBRACON, 2004a.

REGO, J. H. S. As cinzas de casca de arroz (CCAs) cristalina e amorfa como adição mineral ao cimento - aspectos das microestruturas das pastas. 2004b.274 f. Tese (Doutorado em Estruturas e Construção Civil) - Universidade de Brasília, Brasília, DF, 2004b.

SUGITA, S.; YU, Q.; SHOYA, M.; TSUKINAGA, Y.; ISOJIMA, Y. On the semiindustrial production on highly reactive rice husk ash and it effects on cement and concrete properties. In:INTERNATIONAL CONGRESS ON THE CHEMISTRY OF CEMENT, 10 ${ }^{\text {th }}, 1997$, Gothenburg, Sweden.Proccedings... vol. 3, p. 173-182.

WONGLON, T. O.; SANTOS, J. L. K., SILVEIRA, A. A. Avaliação do desempenho de concretos com incorporação de cinza de casca de arroz submetidos à reação álcaliagregado. Passo Fundo, RS. 2002. 7p. XVII CONGRESSO REGIONAL DE INICIAÇÃO CIENTÍFICA E TECNOLÓGICA EM ENGENHARIA, 17.; FEIRA DE PROTÓTIPOS, 3., 2002, Passo Fundo. 